\title{
Opinion
}

\section{What IBD Physicians Can Learn from Major League Baseball Managers}

\author{
Nicholas V. Costrini, MD, PhD, MBA* \\ Gastroenterology Associates of Big Bend, Tallahassee, FL, USA
}

"Corresponding author

Nicholas V. Costrini, MD, PhD, MBA

Gastroenterology Associates of Big Bend, Tallahassee, FL, USA; E-mail: drcostn@gmail.com

Article information

Received: November It, 2019 ; Accepted: November 4 ${ }^{\text {th }}$, 2019; Published: November 6 th $^{\text {th }} 2019$

\section{Cite this article}

Costrini NV. What IBD physicians can learn from major league baseball managers. Gastro Open J. 20I9; 4(I): 7-8. doi: I0.17/40/GOJ-4-I30

$Y^{\prime}$ ogi Berra philosophized, "You can observe a lot by just watching." Physicians managing inflammatory bowel disease (IBD) patients are constantly exposed to the recent literature, the visiting pharmaceutical representatives, and to the valuable presentations by the academic experts at the annual meetings. In my opinion, these presentations too often are advanced in a vacuum of unconvincing compartmentalization rather than as a well-choreographed management strategy that considers both the impact of any IBD drug and the nearly certain likelihood of a patient's failed response or eventual relapse. Stated another way, what is most often missed, only mentioned as an aside, and almost never clearly defined is an agent's place within the context of management of the entire course of the disease. Twenty years into the new century with the current and evolving list of IBD drugs, it would be valuable to much more often and with authority present specific management algorithms that offer the highest likelihood of remission. ${ }^{1,2}$ Having a progressively enlarging menu of partially effective drugs is no longer satisfactory. I give you Major League Baseball (MLB).

We appropriately view the physician's role as that of the manager of the IBD case and particularly as manager of the medications employed. As an instruction, I offer what we can learn from MLB managers as we observe the well-defined strategy in calling Starting and Relief Pitchers to the mound. ${ }^{3}$

1. Great Pitching (i.e. The first IBD drug employed) beats Great Hitting (i.e. moderate to severe IBD). Both starting and Relief Pitching are necessary. In IBD, we have good but not great drugs at the present time. Follow-up (i.e. relief) medications are an essential part of the strategy for IBD. Any discussion of a specific drug must include a recommendation for use in an over-all strategy leading to remission and change in the natural history of IBD.
2. Starting Pitchers seldom hold the mound past six innings.

3. Starting Pitchers' inning-by-inning earned run averages (ERA) rise after the fourth inning.

4. Managers monitor the Starting Pitcher effectiveness (ERA per inning); in IBD, clinical status and fecal calprotectin require intense monitoring ${ }^{3}$ which has been lack-luster for decades.

5. In MLB managers know the bullpen expertise and prior work; in IBD, physicians must know the classes of drugs in the IBD armamentarium.

a. Mesalamine/Steroids/Immunosuppressants/Biologics/ Small molecules

b. Make decision based upon disease/activity/urgency of need/prior drugs exposure

6. Starting Pitchers wins $90 \%$ of Cy Young (best pitcher of the year) Awards even though they seldom pitch a complete game. Similarly, the starting biologic should be expected to bring about complete remission in only a quarter of the cases. ${ }^{4-6}$ Discuss a total medication strategy with patients. Advise that non-responsiveness and relapse are likely and the management strategy provides for these eventualities.

7. The Relievers have lower ERAs than the Starting Pitchers and promote winning seasons. Consider Anti-TNFs, T-Cell Migration Inhibitors, IL 12/23 Inhibitors, JAK inhibitors as essential management choices which should be outlined in the course management from the outset. To be clear, do not cling to the idea that the first biologic will secure long-term remission. Rather, plan with the patient that a change will be re- 
quired and seek the ideal time and agent for the change.

8. For a Quality Start in Baseball, the pitcher goes six innings allowing less than three runs. For the first biologic drug used in IBD, expect a response in $40-50 \%$ of patients by $2-10$ weeks. $^{7}$

9. In the prior century, Starting Pitchers commonly pitched complete games. In this century, they are not expected to and do not always win. Indeed, the three best starting pitchers of the past twenty years (Randy Johnson, Pedro Martinez, and Roger Clemens) had a combined winning percentage of only $66 \%$. Current starting IBD drugs fare only half as well in maintaining remission. In IBD, in this century, do not expect the starting biologic to go the distance. Rather, prepare all involved for an expeditious change as the expected failure or relapse arrives.

10. Relief Pitchers (middle inning and closers) have won $9 \mathrm{Cy}$ Young Awards. MLB managers decide upon the reliever based upon the batters coming to the plate, the inning, and the score. The all-important closer may be the most reliable pitcher on the staff, i.e., Mariano Rivera. In IBD, follow-up medications can be expected to be moderately effective when starting drugs have become ineffective. Perhaps an augmented 15-20\% remission rate can be expected from follow-up drugs. ${ }^{8}$ Hence, when the second drug is started, begin to consider your closer as there is an eighty-percent chance it will be needed.

11. Know when to face a loss. Finish; review the runs, hits, errors and strategy as there is another game tomorrow. Consider hiring another premier reliever. In IBD, know when to prepare for surgery, review the course of responses and remissions. Seek the better drug on the horizon.

The above list of comparisons is designed in a lighthearted way to stress the too-often over-looked reality that no current, single-agent is likely to alter the natural history of the disease in the IBD population as a whole. ${ }^{9}$ It may be effective in only ten to twenty percent of patients. A facile understanding of the evolving classes of IBD drugs is paramount; their timely and strategic introduction should promote a greater proportion of long-term remissions. That is a winning strategy. We cannot, however, win them all. Ted Williams said it best. "Baseball is the only endeavor where a man can succeed 3 times in 10 and be considered a good performer." That is about where we are in IBD management.

\section{REFERENCES}

1. Colombel JF, Panaccione R, Bossuyt P, et al. Effect of tight control management on Crohn's disease (CALM): A multcentre, randomized, controlled phase 3 trial. Lancet. 2018; 390: 2779-2789. doi: 10.1016/S0140-6736(17)32641-7

2. Ungaro R, Colombel JF, Lissoos T, et al. A treat-to-target update in ulcerative colitis: A systematic review. Amer J Gastro. 2019; 114: 874-883. doi: 10.14309/ajg.0000000000000183

3. Baseball-Reference. MLB stats, scores, history, and records, 2019. Web site. Baseball-Reference.com. Accessed October 31, 2019.

4. Sandborn WJ, Feagan BG, Rutgeerts P, et al. Vedolizumab as induction and maintenance therapy for Crohn's disease. $N$ Engl J Med. 2013; 369: 711-721. doi: 10.1056/NEJMoa1215739

5. Hanauer SB, Feagan BG, Lichtenstein GR, et al. Maintenance infliximab for Crohn's disease: The ACCENT I randomized trial. Lancet. 2002; 359: 1541-1549. doi: 10.1016/S0140-6736(02)085124

6. Colombel JF, Sandborn WJ, Rutgeerts P, et al. Adalimumab for maintenance of clinical response and remission in patients with Crohn's disease. Gastroenterology. 2007; 132(1): 52-65. doi: 10.1053/j. gastro.2006.11.041

7. Vasudevan A, Gibson PR, vanLangenberg DR. Time to clinical response and remission for therapeutics in inflammatory bowel diseases: What should the clinician expect, what should patients be told. World J Gastroenterol. 2017: 23(35): 6385-6402. doi: 10.3748/ wjg.v23.i35.6385

8. Sandborn WJ, Rutgeerts P, Gasink C, et al. Long-term efficacy and safety of ustekinumab for Crohn's disease through the second year of therapy. Aliment Pharmacol Ther. 2018: 48(1): 65-77. doi: 10.1111/apt.14794

9. Murthy SK, Begum J, Benchimol EL, et al. Introduction of anti-TNF therapy has not yielded expected declines in hospitalization and intestinal resection rates in inflammatory bowel diseases: A population-based interrupted time series study. Gut. 2019; pii: gutjnl-2019-318440. doi: 10.1136/gutjnl-2019-318440 